J. MED. MICROBIOL. - VOL. 19 (1985) 45-53

(C) 1985 The Pathological Society of Great Britain and Ireland

\title{
PSE-4 BETA LACTAMASE: A SEROTYPE-SPECIFIC ENZYME IN PSEUDOMONAS AERUGINOSA
}

\author{
D. M. Livermore, T. L. Pitt*, C. S. Jones, Judy A. Crees-Morris* \\ and Rosamund J. Williams
}

Department of Medical Microbiology, The London Hospital Medical College, Turner Street, London E1 and *Division of Hospital Infection, Central Public Health Laboratory, Colindale Avenue, London NW9

\begin{abstract}
SUMMAR Y. PSE- 4 enzyme is the most common plasmidic $\beta$ lactamase in Pseudomonas aeruginosa but its production is invariably non-transferable by conjugation. Of 20 PSE- $4^{+}$isolates from 10 separate sources, 16 were serotype $O: 16$ and two belonged to the related $O: 2(b)$ serotype. One of the two remaining organisms was not O-typable and the other was agglutinated by several unrelated antisera. Examination of additional O:16 strains confirmed the unusual frequency of PSE-4 enzyme in this serotype. None of the PSE- $4^{+}$strains was able to transfer carbenicillin resistance in mating experiments and none contained extrachromosomal DNA. Two explanations of the relationship between enzyme production and $\mathrm{O}$ antigenicity are proposed. PSE-4 production may be transmissible, perhaps by transduction, between strains of $0: 16$ or related serotypes, or PSE- $4^{+} P$. aeruginosa may represent a disseminated subtype. A third hypothesis, that the PSE- 4 coding element carried serotype determinants, was discounted. PSE- $4^{+}$and PSE-4 ${ }^{-} P$. aeruginosa strains of O:16 and related serotypes were found to represent a definite cluster by their phage-susceptibility pattern and pyocin type (type 1). The only characters linked to PSE-4 production were resistance to spectinomycin, streptomycin and sulphonamide and the genes responsible for these characters seemed to occur on the PSE-4 coding element.
\end{abstract}

\section{INTRODUCTION}

Various plasmid-mediated $\beta$ lactamases, may cause penicillin and cephalosporin resistance in gram-negative bacteria (Matthew, 1979; Foster, 1983). Most of these enzymes have now been observed in Pseudomonas aeruginosa (Jacoby, Sutton and Medeiros, 1980) but their frequency in this species remains low. In a recent multicentre survey we detected $\beta$ lactamases considered by Foster (1983) to be plasmidic in only $2 \%$ of 1866 P. aeruginosa isolates (Williams et al., 1984). In contrast, Whitaker, Hajipieris and Williams (1983) detected these enzymes in $43 \%$ of 1000 gram-negative rods 
isolated from patients at The London Hospital during 1982. The frequency of various enzyme types also varied between $P$. aeruginosa and other gram-negative rods; in $P$. aeruginosa we found that PSE-4 (Dalgleish enzyme) (Newsom, Sykes and Richmond, 1970) was the most common (Williams et al., 1984) whereas TEM-1 is by far the most frequent amongst gram-negative rods as a whole (Matthew, 1979; Whitaker et al., 1983). Other groups have reported PSE-4 production by $P$. aeruginosa strains from Great Britain (King et al., 1980), France (Labia et al., 1977; Jouvenot, Bonin and Michel-Briand, 1983), the Netherlands (Stobberingh, Houben and van Boven, 1982) and Australia (Sinclair and Holloway, 1982), confirming that this enzyme is widely scattered in the species. PSE-4 is, however, unknown outside $P$. aeruginosa (Matthew, 1979; Foster, 1983) and its production is invariably non-transmissible by conjugation even within the species. (Jacoby and Matthew, 1979). Recent studies on Australian PSE- $4^{+}$isolates have indicated that enzyme production is encoded by a transfer-deficient chromosomally-integrating transposon (Sinclair and Holloway, 1982).

The wide distribution of PSE-4 $\beta$ lactamase thus presents a paradox and this has been investigated in the present study. Enzyme production has been shown to be almost restricted to a single serogroup and a close degree of similarity between strains has been demonstrated within this group.

\section{MATERIALS AND METHODS}

Strains of $P$. aeruginosa. Eighteen isolates that produced PSE-4 co-focusing $\beta$ lactamases were from a national survey of antibiotic resistance in $P$. aeruginosa (Williams et al., 1984). Two PSE-4 ${ }^{+}$isolates were from an earlier study (Livermore, Williams and Williams, 1981). $P$. aeruginosa Dalgleish (Newsom et al., 1970) was used as a PSE-4-producing reference strain. Forty-one strains which reacted with $\mathrm{O}$ sera against two or more of the antigenically related group-II serotypes O:2(a), O:2(b), O:5 and O:16 and 30 further strains of serotype O:16 were received by the Division of Hospital Infection, Central Public Health Laboratory, Colindale, during 1981-1982. Strains of other serotypes were from our culture collection. P. aeruginosa PU21 ilv leu rif str was described by Jacoby (1974) and plasmid pUZ8, contained in Escherichia coli K12 J53-2 pro met nal, was described by Hedges and Matthew (1979).

Typing of cultures. Cultures were serotyped according to the International Antigenic Typing Scheme described by Liu et al. (1983) by the methods of Pitt (1981). Antisera against the type strains of serotypes O:2(b) and O:5(d) of Veron (1961) were used for the sub-division of serotypes O:2 and O:5. Phage typing was performed as described by Asheshov (1974) and pyocin typing as described by Govan and Gillies (1969).

Minimum inhibitory concentrations (MICs) were determined by an agar dilution technique with doubling dilutions of antibiotics in Diagnostic Sensitivity Test (DST) agar (Oxoid CM261). Inocula contained $c .10^{4}$ cells from overnight nutrient-broth culture. Results were read after incubation for $18 \mathrm{~h}$ at $37^{\circ} \mathrm{C}$ and MICs were defined as the lowest antibiotic concentration at which there was no visible growth.

Examination of $\beta$-lactamase production. Carbenicillin-resistant organisms (MIC >128 $\mathrm{mg} / \mathrm{L}$ ) were examined for constitutive $\beta$-lactamase expression by the EDTA-nitrocefin technique (Williams et al., 1984). Extracts containing $\beta$ lactamase were prepared from organisms that gave a positive reaction by the 'washed slope' method of Livermore, Maskell and Williams (1984) and were subjected to isoelectric focusing by the method of Matthew et al. (1975). Enzyme identification was by comparison with standard TEM-1 and 2, OXA-1, 2 and 3, PSE-1, 2, 3 and 4, SHV- 1 and HMS- $1 \beta$ lactamases. Larger amounts of $\beta$ lactamases for enzyme activity studies were prepared from logarithmic phase nutrient-broth cultures by the method of Williams et al. (1984) with the modification that enzyme was liberated by two freeze-thaw cycles instead of by sonication. Hydrolytic activity was examined by UV spectrophotometric assay (O'Callaghan, 
Muggleton and Ross, 1969; Waley, 1974) with substrates at $1 \mathrm{~mm}$ concentration in $0.1 \mathrm{M}$

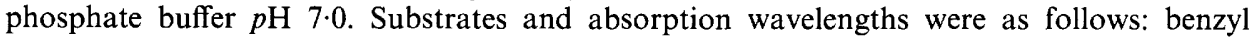
penicillin (Glaxo Group Research), $235 \mathrm{~nm}$; carbenicillin (Beecham Research Laboratories), 235 $\mathrm{nm}$; oxacillin (Sigma Chemical Co.), $263 \mathrm{~nm}$; and cephaloridine (Glaxo Group Research), 295 $\mathrm{nm}$.

Genetic studies on PSE-4 production. Conjugative transfer of carbenicillin resistance from PSE- $4^{+}$isolates to $P$. aeruginosa strain PU21 was initially attempted by mating the organisms in nutrient broth (Livermore and Williams, 1982). Modifications of this method were also attempted whereby donor and recipient were mixed either on nutrient agar plates or on $0.45-\mu \mathrm{m}$ pore size membrane filters (Millipore Corporation). Transconjugants were selected on DST agar containing rifampicin (Gruppo Lepetit SA, Milan) $100 \mathrm{mg} / \mathrm{L}$ and carbenicillin $250 \mathrm{mg} / \mathrm{L}$.

Transfer of the PSE-4 coding element from $P$. aeruginos $a$ Dalgleish was also attempted by a recombinant plasmid technique. This organism was grown overnight in $10 \mathrm{ml}$ of nutrient broth and the cells were harvested at $5000 \mathrm{~g}$ and resuspended in $0.5 \mathrm{ml}$ of a $50 \times$ concentrated saline suspension of a 6-h nutrient-broth culture of $E$. coli J53-2 (pUZ8). The mixture (100 $\mu \mathrm{l}$ ) was spread across a DST plate and incubated for $24 \mathrm{~h}$ at $37^{\circ} \mathrm{C}$. Cells were then washed into saline $0.9 \% \mathrm{w} / \mathrm{v}$ and transferred to DST agar containing tetracycline (Lederle) $50 \mathrm{mg} / \mathrm{L}$ and cefoxitin (Merck, Sharpe and Dohme) $100 \mathrm{mg} / \mathrm{L}$. P. aeruginosa Dalgleish transconjugants with the pUZ8 plasmid were picked off after incubation for 2 days at $37^{\circ} \mathrm{C}$ and confirmed as oxidase positive and kanamycin resistant (MIC $>256 \mathrm{mg} / \mathrm{L}$ ). One of these transconjugants was then mated with $P$. aeruginosa strain PU21 by growing both organisms overnight in $10-\mathrm{ml}$ volumes of nutrient broth. The cells were harvested at $5000 \mathrm{~g}$ and the pellets mixed in $0.5 \mathrm{ml}$ of saline, $0.1 \mathrm{ml}$ of which was spread on a DST agar plate. After overnight incubation the cells were washed into saline and transferred to DST agar containing carbenicillin $250 \mathrm{mg} / \mathrm{L}$, kanamycin $200 \mathrm{mg} / \mathrm{L}$ and rifampicin $100 \mathrm{mg} / \mathrm{L}$. Transconjugants, designated PU21 (pUZ8 : : PSE-4) were confirmed as producers of PSE-4 $\beta$ lactamase by isoelectric focusing and as auxotrophs by their inability to grow on mineral salts agar containing D-glucose $0.5 \% \mathrm{w} / \mathrm{v}$ as sole carbon and energy source. $P$. aeruginosa strain PU21 (pUZ8 : : PSE-4) was mated with prototrophic $P$. aeruginosa isolates of various serotypes by the same method used for crosses between $P$. aeruginosa Dalgleish (pUZ8) and strain PU21 with the modification that transconjugant selection was on mineral salts agar containing D-glucose $0.5 \% \mathrm{w} / \mathrm{v}$ and carbenicillin $250 \mathrm{mg} / \mathrm{L}$.

Organisms were examined for plasmid DNA by the method of Kado and Liu (1981). Plasmid electrophoresis was on $0.7 \%$ agarose vertical slab gels with a 'Protean' apparatus (Bio-Rad Laboratories, Watford). The gel thickness was $3 \mathrm{~mm}$ and a constant voltage of $160 \mathrm{~V}$ was

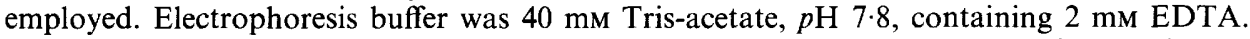
Plasmids were visualised by staining with aqueous ethidium bromide $0.5 \mathrm{mg} / \mathrm{L}$ for $30 \mathrm{~min}$ and photographed, with UV illumination, with a Polaroid CU-5 Land camera with type 655 or 667 film. Plasmid DNA for restriction endonuclease analysis was extracted by a scaled up version of the method of Kado and Liu (1981) that used $50 \mathrm{ml}$ of culture. Restriction cleavage was performed with enzymes EcoRI and HindIII (Sigma Chemical Co., St Louis, MO); the methods were those recommended by the manufacturers. Fragments were electrophoresed in $0.8 \%$ agarose gels using a horizontal apparatus (Bio-Rad DNA 'Sub-Cell'). Buffers and visualisation methods were as for plasmid electrophoresis.

\section{RESULTS}

\section{Serotyping of PSE-4 ${ }^{+} P$. aeruginosa}

Twenty $P$. aeruginosa isolates that produced $\beta$ lactamases which aligned with PSE-4 enzyme from $P$. aeruginos $a$ on isoelectric focusing gels were examined initially. These organisms were from our survey and from earlier collections. Sixteen organisms, from eight separate sources, reacted with antiserum to type 0:16 and two, from separate sources, reacted with antiserum to type O:2(b). These serotypes are closely related. Of the remaining two organisms one was not agglutinated by any antiserum 
and was termed not typable and the other was agglutinated by antisera to types $O: 3$, $\mathrm{O}: 9, \mathrm{O}: 10$ and $\mathrm{O}: 13$ and was termed polyagglutinable. $P$. aeruginosa Dalgleish was serotype O:16.

\section{Examination of $O: 16$ and other group-II P. aeruginosa strains for carbenicillin resistance and PSE-4 production}

Examination of serotype O:16 and other group-II P. aeruginosa strains received by the Division of Hospital Infection, Central Public Health Laboratory, Colindale revealed that 12 out of 30 serotype $O: 16$ strains were resistant to carbenicillin $128 \mathrm{mg} / \mathrm{L}$ and seven of these produced $\beta$ lactamases indistinguishable from PSE- 4 by isoelectric focusing. Seven of 41 other group-II isolates were carbenicillin resistant and one produced a $\beta$ lactamase of identical pI (c. 5.3) to the PSE-4 enzyme.

\section{Comparison of PSE-4 $4^{+}$and PSE-4- strains of serotype O:16 and other group-II serotypes of $P$. aeruginosa}

The initial studies described above yielded 20 epidemiologically distinct strains of $P$. aeruginosa that produced $\beta$ lactamases that aligned with PSE-4 in electrofocusing experiments (table I). Hydrolysis assays confirmed that these enzymes had similar activity to the PSE-4 enzyme from $P$. aeruginosa Dalgleish (table I). None of the organisms was able to transfer carbenicillin resistance to strain PU21 in simple broth and plate mating experiments and none contained extrachromosomal DNA.

These strains were compared with 20 distinct carbenicillin-susceptible PSE-4strains, 14 of serotype O:16 and six of other group-II serotypes. All the PSE-4 ${ }^{+}$isolates were of pyocin type 1 , as were 19 out of 20 of the PSE- $4^{-}$strains, the exception being a strain of serotype O:16 and pyocin type 10. PSE-4 ${ }^{+}$and PSE-4- isolates were generally susceptible to phages $44,68,109$ and 1214 , but were usually resistant to the other phages tested. All the PSE-4 ${ }^{+}$strains were highly resistant to spectinomycin (MIC $>2048 \mathrm{mg} / \mathrm{L}$ ), streptomycin (MIC 256-512 mg/L) and sulphamethoxazole (MIC $>1024 \mathrm{mg} / \mathrm{L}$ ). PSE-4- strains were much less resistant to these antibiotics.

\section{Transfer of the determinant for PSE-4 enzyme production from P. aeruginosa Dalgleish} by recombinant plasmid formation

A PSE-4 enzyme-producing transconjugant, designated PU21(pUZ8:: PSE-4), was obtained. Agarose gel electrophoresis of 10 separate clones indicated that this organism had acquired a single plasmid of mol. wt $38.8 \times 10^{6}$ in contrast to the value of $34 \times 10^{6}$ for plasmid pUZ8. These results indicated that a recombinant plasmid had been formed between pUZ8 and the PSE-4 coding element and that the latter had a mol. wt of $4.8 \times 10^{6}(7.2 \mathrm{~Kb}$ pairs). Extrachromosomal DNA was not detected in $P$. aeruginosa Dalgleish and this suggested that the PSE-4 coding element was incorporated into the chromosome of this organism. Analysis of fragments obtained by endonuclease treatment did not indicate an additional site for EcoRI in the (pUZ8 : : PSE-4) plasmid compared with pUZ8 alone, but two extra sites for HindIII were detected.

Sero- and phage-typing results for $P$. aeruginosa Dalgleish, $P$. aeruginosa Dalgleish 
TABLE I

Sources, serotypes and B-lactamase activities of epidemiologically distinct PSE-4 ${ }^{+}$strains

\begin{tabular}{|c|c|c|c|c|c|c|}
\hline \multirow[b]{2}{*}{ Strain } & \multirow[b]{2}{*}{ Source } & \multirow[b]{2}{*}{ Serotype } & \multicolumn{4}{|c|}{$\begin{array}{l}\text { Relative hydrolysis } \\
\text { rate of }\end{array}$} \\
\hline & & & Pen G & Carb & Ceph & Oxa \\
\hline Dalgleish & Newsom et al. (1970) & $0: 16$ & 100 & 167 & 11.1 & $9 \cdot 1$ \\
\hline $\mathrm{R} 25$ & London Hospital & $0: 16$ & 100 & 138 & $9 \cdot 4$ & $8 \cdot 1$ \\
\hline R57 & Birmingham & $0: 16$ & 100 & 146 & $10 \cdot 1$ & $8 \cdot 4$ \\
\hline M145 & Irvine & $O: 16$ & 100 & 122 & $10 \cdot 8$ & $8 \cdot 6$ \\
\hline M202 & Bangor (Wales) & NT & 100 & 147 & $9 \cdot 8$ & $8 \cdot 7$ \\
\hline M423 & Birmingham & $O: 16$ & 100 & 133 & $9 \cdot 5$ & $9 \cdot 3$ \\
\hline M817 & Guys, London & $O: 16$ & 100 & 127 & $13 \cdot 3$ & $9 \cdot 1$ \\
\hline M1235 & Liverpool & $0: 16$ & 100 & 165 & $12 \cdot 5$ & $10 \cdot 6$ \\
\hline M1767 & St Thomas's, London & $\mathrm{O}: 2(\mathrm{~b})$ & 100 & 110 & $10 \cdot 0$ & $7 \cdot 7$ \\
\hline M2138 & York & $0: 16$ & 100 & 148 & $10 \cdot 9$ & 8.9 \\
\hline M2207 & Newcastle upon Tyne & $0: 16$ & 100 & 114 & $8 \cdot 3$ & $6 \cdot 5$ \\
\hline M2225 & Newcastle upon Tyne & PA & 100 & 122 & $9 \cdot 9$ & $10 \cdot 6$ \\
\hline C4218 & Edgware & $\mathrm{O}: 16$ & 100 & 136 & $10 \cdot 2$ & $8 \cdot 4$ \\
\hline C4918 & Southampton & $0: 16$ & 100 & 151 & $10 \cdot 3$ & $8 \cdot 5$ \\
\hline C5156 & Kent and Sussex & $0: 16$ & 100 & 136 & $9 \cdot 9$ & $7 \cdot 8$ \\
\hline C5414 & Southport & O:II & 100 & 136 & $9 \cdot 9$ & $7 \cdot 0$ \\
\hline C5709 & Llandough & $O: 16$ & 100 & 123 & $3 \cdot 8$ & $8 \cdot 7$ \\
\hline C6061 & Newcastle upon Tyne & O:16 & 100 & 128 & $10 \cdot 1$ & $8 \cdot 5$ \\
\hline C6157 & Hammersmith & $0: 16$ & 100 & 151 & 10.9 & $7 \cdot 7$ \\
\hline C6463 & Epsom & $0: 16$ & 100 & 122 & $10 \cdot 5$ & $6 \cdot 2$ \\
\hline
\end{tabular}

$\mathrm{NT}=$ Not typable; $\mathrm{PA}=$ polyagglutinable (agglutinated with antisera to types $\mathrm{O}: 3, \mathrm{O}: 9, \mathrm{O}: 10$ and $\mathrm{O}: 13$ ). Pen $\mathrm{G}=$ benzylpenicillin; $\mathrm{Carb}=$ carbenicillin; $\mathrm{Ceph}=$ cephaloridine; Oxa = oxacillin.

TABLE II

Serology, phage typing and antibiograms of P. aeruginosa strains Dalgleish and PU21 and their transconjugants

\begin{tabular}{|c|c|c|c|c|c|c|c|c|}
\hline \multirow[b]{2}{*}{ Strain } & \multirow[b]{2}{*}{ Serotype } & \multirow{2}{*}{$\begin{array}{c}\text { Phage } \\
\text { suscepti- } \\
\text { bility } \\
\text { pattern }\end{array}$} & \multicolumn{6}{|c|}{$\mathrm{MIC}(\mathrm{mg} / \mathrm{L})$ of } \\
\hline & & & $\begin{array}{c}\text { Carbeni- } \\
\text { cillin }\end{array}$ & $\begin{array}{c}\text { Strepto- } \\
\text { mycin }\end{array}$ & $\begin{array}{l}\text { Spectino- } \\
\text { mycin }\end{array}$ & $\begin{array}{l}\text { Sulphameth- } \\
\text { oxazole }\end{array}$ & $\begin{array}{l}\text { Kana- } \\
\text { mycin }\end{array}$ & $\begin{array}{l}\text { Tetra- } \\
\text { cycline }\end{array}$ \\
\hline $\begin{array}{l}P . \text { aeruginosa } \\
\text { Dalgleish } \\
P . \text { aeruginosa }\end{array}$ & $\mathrm{O}: 16$ & A & $>2048$ & 512 & $>2048$ & $>1024$ & 32 & 8 \\
\hline $\begin{array}{l}\text { Dalgleish (pUZ8) } \\
\text { P. aeruginosa }\end{array}$ & $0: 16$ & A & $>2048$ & 512 & $>2048$ & $>1024$ & $>256$ & $>128$ \\
\hline $\begin{array}{l}\text { PU 21 } \\
\text { P. aeru }\end{array}$ & $0: 16$ & B & 32 & $>2048$ & 128 & 128 & 64 & 8 \\
\hline PU21(pUZ8 : : PSE-4) & $0: 16$ & B & $>2048$ & $>2048$ & $>2048$ & $>1024$ & $>256$ & $>128$ \\
\hline
\end{tabular}

$A=$ susceptible to phages 21,68 and $1214 ; \mathrm{B}=$ susceptible to phages $7,16,21,44,68,73, \mathrm{~F} 7, \mathrm{~F} 8,109,119 \mathrm{X}$, 1214 and M6.

(pUZ8), $P$. aeruginosa PU21 and $P$. aeruginosa PU21(pUZ8:: PSE-4) are given in table II. All these strains were of serotype $0: 16$ but gave weak reactions with antisera to types O:2(a) and O:2(b). P. aeruginosa Dalgleish and its (pUZ8) ${ }^{+}$transconjugant were susceptible to only three phages whereas strains PU21 and PU21(pUZ8:: PSE-4) were susceptible to 12. Using strain PU21 (pUZ8::PSE-4) as a donor we transferred the pUZ8 : : PSE-4 recombinant plasmid into $P$. aeruginosa strains of $\mathrm{O}$ serotypes $2,4,8$, 10 and 15 and in no case was plasmid acquisition associated with changes in serotype or 
phage susceptibility. Strain PU21(pUZ8:: PSE-4) and other transconjugants with the (pUZ8 : : PSE-4) plasmid acquired high level resistance to carbenicillin, spectinomycin, sulphonamide, tetracycline and kanamycin (table II). The last two resistances were encoded by plasmid pUZ8, and only the first three were attributable to the PSE-4 coding element. Acquisition of streptomycin resistance could not be monitored in strain PU21 because this strain was intrinsically extremely resistant to this antibiotic. Streptomycin resistance was acquired, however, by recipients when strain PU21(pUZ8:: PSE-4) was the donor.

The pUZ8 : : PSE-4 plasmid was wholly stable in strain PU21 and the O:4, O:8 and $\mathrm{O}: 15$ transconjugants during repeated nutrient-broth subculture, but tended to be lost by the $0: 10$ and, surprisingly, the $0: 2$ transconjugants.

\section{DISCUSSION}

Sixteen of the $20 \mathrm{PSE}-4^{+}$strains of $P$. aeruginosa from our survey and from earlier collections of strains reacted with antisera to type $0: 16$ and two with antisera to type $\mathrm{O}: 2$ (b). These serotypes, together with $\mathrm{O}: 2(\mathrm{a})$ and $\mathrm{O}: 5$, are closely related, sharing a common group antigen (group II), and may be distinguished only by the use of absorbed sera (Pitt, 1981). Moreover, antigenic drift between these types has been observed in isolates from the same source over a prolonged period (Pitt, unpublished observations). The only non-group-II PSE-4+ isolates found were a non-typable strain and one which was agglutinated by several unrelated antisera. Because only $9 \%$ of $P$. aeruginosa are of serotype O:16 and only 16\% have the common group-II antigen (Pitt, 1981) it appears unlikely that this distribution of PSE-4 enzyme was a product of chance $\left(\mathrm{p}<10^{-7}\right)$. These observations led us to examine further O:16 and group-II $P$. aeruginosa strains for PSE-4 $\beta$ lactamase and seven out of 30 O:16 strains were found to be enzyme producers. This frequency was significantly higher than that for the whole species in which only 18 PSE-4 ${ }^{+}$organisms were found amongst 1866 isolates (Williams et al., 1984) ( $\chi^{2}$ test: $\left.p<0 \cdot 01\right)$. From these observations we conclude that PSE-4 $\beta$ lactamase is largely, if not wholly, serotype associated in $P$. aeruginosa from British hospitals. This result may not be valid on an international scale because Jouvenot and colleagues (1983) have reported PSE-4 enzyme from $P$. aeruginosa of various serotypes from a single French hospital. However, these authors did not provide precise details of the enzyme's distribution amongst the serotypes.

A likely explanation of our data is that the PSE-4 coding element is restricted in its distribution by its transmissibility. Extrachromosomal DNA was absent from all our PSE-4+ isolates and it seems likely that enzyme production was encoded by an element similar or identical to the PSE-4 coding chromosomally-integrating transposon Tn2521 described from Australian isolates of $P$. aeruginosa (Sinclair and Holloway, 1982). All our isolates resembled the Australian organisms in resistance pattern (resistant to carbenicillin, spectinomycin, streptomycin and sulphonamides) and the element transferred from $P$. aeruginosa Dalgleish was identical to $\operatorname{Tn} 2521$ in having a mol. wt of $4.8 \times 10^{6}$ and in its susceptibility to restriction endonucleases. However, the mechanism of dissemination is not clear and we were unable to obtain conjugative transfers from wild types to strain PU21, which is also serotype O:16. Similar failures to transfer PSE-4 production by conjugation have been reported by other investigators (Sykes and Matthew, 1976; Jacoby and Matthew, 1979; Sinclair and Holloway, 1982; 
Jouvenot et al., 1983). Although we transferred PSE-4 enzyme production to strain PU2 1 by forming a recombinant plasmid between the PSE-4 coding element and the Inc P-1 plasmid pUZ8, we do not consider this finding to be relevant to the present distribution of the enzyme. Such PSE-4 coding Inc P-1 recombinant plasmids are transferable to $E$. coli (Hedges and Matthew, 1979; Jones, unpublished data) whereas PSE-4 enzyme production has never been observed outside $P$. aeruginosa. Recombinant plasmid formation does, however, represent a mechanism by which the PSE-4 coding element may ultimately achieve a wider distribution. It is possible that transfer of the PSE-4 coding element occurs in nature via a serotype-specific phage. Transduction of Tn2521 was described by Sinclair and Holloway (1982) and such a mechanism might explain the distribution of the enzyme in nature.

A second explanation of the association between serotype and PSE-4 $\beta$ lactamase is that enzyme production is essentially non-transmissible and that enzyme producing isolates represent a 'subtype'. This hypothesis predicted greater similarity within PSE-4 ${ }^{+} P$. aeruginosa than between group-II PSE-4- strains. However, phage and pyocin typing revealed that group-II strains represented a cluster regardless of $\beta$-lactamase production. The only PSE-4 linked characters were resistance to streptomycin, spectinomycin and sulphonamide and these were determined by the PSE-4 coding element itself, at least in the Dalgleish strain.

A final possible explanation of the linkage between PSE-4 production and serotype was that the PSE-4 coding element carried serotype determinants. This hypothesis was largely discounted by transfer of the (pUZ8:: PSE-4) recombinant plasmid into $P$. aeruginosa strains of various serotypes. None of these organisms exhibited changes in surface characteristics as revealed by sero- and phage-typing. It may still be argued that the PSE-4 coding element only affects serotype once inserted into the chromosome. This possibility was not disproven but seems unlikely since the reported insertion site of Tn2521 (Sinclair and Holloway, 1982) is remote from the genes known to affect serotype (Holloway, Krishnapillai and Morgan, 1979).

In summary, we demonstrated that PSE-4, which is the most common plasmidic $\beta$ lactamase in $P$. aeruginosa, was largely confined to strains of serotype $0: 16$ and closely related serotypes. This association may reflect limited transmissibility of the PSE-4 coding element, or may indicate that PSE $-4^{+} P$. aeruginos $a$ are a distinct subtype of the species. It is also apparent from our studies that the designation of PSE-4 as a 'plasmid-mediated $\beta$ lactamase' (Matthew, 1979; Foster, 1983) is misleading. This enzyme has little in common with the other plasmidic $\beta$ lactamases, which often occur on widely transferable elements. In many ways, the earlier classification of PSE-4 as an unusual chromosomal $\beta$ lactamase (Sykes and Matthew, 1976) seems more appropriate.

DML, RJW and CSJ are grateful to the participants in our recent survey of antibiotic resistance in $P$. aeruginos $a$ who provided many of the strains used in this study, and to Pfizer Inc. who provided financial assistance.

\section{REFERENCES}

Asheshov E H 1974 An assessment of the methods used for typing strains of Pseudomonas aeruginosa. In: Arseni A (ed) Proceedings of the sixth national congress of bacteriology. Leontiadi Medical Editions, Athens, p 9. 
Foster T J 1983 Plasmid-determined resistance to antimicrobial drugs and toxic metal ions in bacteria. Microbiological Reviews 47:361-409.

Govan J R W, Gillies R R 1969 Further studies in the pyocine typing of Pseudomonas pyocyanea. Journal of Medical Microbiology 2:17-25.

Hedges R W, Matthew M 1979 Acquisition by Escherichia coli of plasmid-borne $\beta$-lactamases normally confined to Pseudomonas spp. Plasmid 2:269-278.

Holloway B W, Krishnapillai V, Morgan A F 1979 Chromosomal genetics of Pseudomonas. Microbiological Reviews 43:73-102.

Jacoby G A 1974 Properties of $R$ plasmids determining gentamicin resistance by acetylation in Pseudomonas aeruginosa. Antimicrobial Agents and Chemotherapy 6:239-252.

Jacoby G A, Matthew M 1979 The distribution of $\beta$-lactamase genes on plasmids found in Pseudomonas. Plasmid 2:41-47.

Jacoby G A, Sutton L, Medeiros A A 1980 Plasmid-determined $\beta$-lactamases of Pseudomonas aeruginosa. In: Nelson J D, Grassi G G (eds) Current chemotherapy and infectious disease. American Society for Microbiology, Washington D.C., pp 769-770.

Jouvenot M, Bonin P, Michel-Briand Y 1983 Frequency of $\beta$-lactamases that are markedly active against carbenicillin in the Pseudomonas aeruginosa strains isolated in a medical school hospital. Journal of Antimicrobial Chemotherapy 12:451-458.

Kado C I, Liu S T 1981 Rapid procedure for detection and isolation of large and small plasmids. Journal of Bacteriology 145:1365-1373.

King J D, Farmer T, Reading C, Sutherland R 1980 Sensitivity to carbenicillin and ticarcillin, and the $\beta$-lactamases of Pseudomonas aeruginosa isolated in the UK in 1978-1979. Journal of Clinical Pathology 33:297-301.

Labia R, Guionie M, Masson J M, Philippon A, Barthelemy M 1977 Beta-lactamases produced by a Pseudomonas aeruginosa strain highly resistant to carbenicillin. Antimicrobial Agents and Chemotherapy 11:785-790.

Liu P V, Matsumoto H, Kusama H, Bergan T 1983 Survey of heat-stable, major somatic antigens of Pseudomonas aeruginosa. International Journal of Systematic Bacteriology 33:256-264.

Livermore D M, Williams R J, Williams J D 1981 Comparison of the $\beta$-lactamase stability and the in vitro activity of cefoperazone, cefotaxime, cefsulodin, ceftazidime, moxalactam and ceftriaxone against Pseudomonas aeruginosa. Journal of Antimicrobial Chemotherapy 8:323-331.

Livermore D M, Williams R J 1982 Role of plasmid-mediated beta-lactamases in the resistance of Pseudomonas aeruginosa to new beta-lactams. In: Periti P, Grassi G G (eds) Current chemotherapy and immunotherapy. American Society for Microbiology, Washington D.C., pp 754-756.

Livermore D M, Maskell J P, Williams J D 1984 Detection of PSE-2 $\beta$-lactamase in enterobacteria. Antimicrobial Agents and Chemotherapy 25:268-272.

Matthew M 1979 Plasmid-mediated $\beta$-lactamases of gram-negative bacteria: properties and distribution. Journal of Antimicrobial Chemotherapy 5:349-358.

Matthew M, Harris A M, Marshall M J, Ross G W 1975 The use of analytical isoelectric focusing for detection and identification of $\beta$-lactamases. Journal of General Microbiology $88: 169-178$.

Newsom S W B, Sykes R B, Richmond M H 1970 Detection of a $\beta$-lactamase markedly active against carbenicillin in a strain of Pseudomonas aeruginosa. Journal of Bacteriology 101:1079-1080.

Pitt T L 1981 A comparison of flagellar typing and phage typing as means of subdividing the $\mathrm{O}$ groups of Pseudomonas aeruginosa. Journal of Medical Microbiology 14:261-270.

O'Callaghan C H, Muggleton P W, Ross G W 1969 Effects of $\beta$-lactamase from gram-negative organisms on cephalosporins and penicillins. In: Hobby G L (ed) Antimicrobial Agents and Chemotherapy-1968. American Society for Microbiology, Washington D.C., pp 57-63.

Sinclair M I, Holloway B W 1982 A chromosomally located transposon in Pseudomonas aeruginosa. Journal of Bacteriology 151:569-579.

Stobberingh E E, Houben A W, van Boven C P A 1982 Distribution and characterisation of $\beta$-lactamase-producing strains isolated in the southern part of The Netherlands. In: Periti P, 
Grassi G G (eds) Current chemotherapy and immunotherapy. American Society for Microbiology, Washington D.C., pp 747-748.

Sykes R B, Matthew M 1976 The $\beta$-lactamases of Gram-negative bacteria and their role in resistance to $\beta$-lactam antibiotics. Journal of Antimicrobial Chemotherapy 2:115-157.

Veron M 1961 Sur l'agglutination de Pseudomonas aeruginosa: subdivision des groupes antigéniques O:2 et O:5. Annals de l'Institut Pasteur 101:456-460.

Waley S G 1974 A spectrophotometric assay of $\beta$-lactamase action on penicillins. Biochemical Journal 139:789-790.

Whitaker S, Hajipieris P, Williams J D 1983 Distribution and type of beta-lactamase amongst 1,000 Gram-negative rod bacteria. In: Spitzy K H, Karrer K (eds) Proceedings of the 13th International Congress of Chemotherapy. Part 89, pp 10-11.

Williams R J, Livermore D M, Lindridge M A, Said A A, Williams J D 1984 Mechanisms of beta-lactam resistance in British isolates of Pseudomonas aeruginosa. Journal of Medical Microbiology 17:283-293. 